\title{
Prospects of Multilevel Communication by Children and Young People in Africa: A Case Study of the South African Children's Parliament
}

\author{
Adebayo Fayoyin, PhD.
}

\begin{abstract}
In many African countries, the Children's Parliament has become a major platform for advocacy, participation and communication for young people. Child rights advocates are optimistic of its transformative role in enhancing the voice of young people and instituting an empowering narrative for social change. However, it is constrained by conceptual and programmatic weaknesses which vitiate its effectiveness as a tool of meaningful participation and communication by children. Using a case study of the South Africa Children's Parliament, this paper examines the prospects of multilevel communication and advocacy by children and young people in the country. Our findings show that the initiative has facilitated upward communication, making the voice of young people heard on major public issues, and horizontal communication, mobilizing them for citizenship engagement and public participation essential for social development. Nonetheless, it is largely tokenistic and events-based. Evidence that the children's parliament reinforces Western epistemologies of child communication is inconclusive. However this question requires further investigation.
\end{abstract}

Keywords: child rights, child communication, activism, participation, social dialogue

\section{INTRODUCTION}

The adoption of the United Nations Convention on the Rights of the Child (UN CRC) in 1989 has led to significant global interest on the participation and communication rights of children, especially on the need to be 'seen and heard' in society (Beers, Invernizzi, and Milne, 2006; Lansdown, 2011, 2010).By right, all children regardless of age, gender, social and economic situation can and should be able to form opinions on issues affecting them; express such opinions and views through a variety of channels; and entitled to unfettered opportunity to communicate (Beers, Invernizzi, and Milne, 2006; Couzens and Mtengeti, 2011). Statutorily, governments (as State Parties to the treaties) are required to assure children's right to communicate freely (Lansdown, 2011:7). Duty bearers, such as adults and other care givers, have a duty of care to ensure that the rights to communicate is realised, and that children's views are given 'due weight' (Jonnson, 2003:78; Lansdown, 2010:80). The child rights dispensation also implies that there is no restriction on what children can discuss once the issue is relevant to them, even on judicial and administrative matters (O'Donelle 2009:6). A major implication of the children right movement is that children could hold adults and decision- makers accountable for realizing these rights and can seek redress on any areas of rights violation. Nevertheless, the children rights treaties make provision for the evolving capacity of children in their communication and participation experience.

The children parliament is a global practice of child participation, aimed at promoting the voice and visibility of children and young people (IPU and UNICEF, 2011:15). It is intended to enhance genuine dialogue, debate and public advocacy by children, promote the agency of young people, and impart democratic ethos and skills. It challenges the perception of children as the vulnerable little citizens, with non-consequential communication rights but as full-fledged individuals, who can hold opinions, express opinions and be seen and heard. Nevertheless, it suffers from derogatory terms like 'mock parliament' or 'junior parliament'.

As an intervention to promote the voice of children and youth people, the children's parliament is a site for exploring multiple communication functions, directions, results and challenges. It provides a platform for an interdisciplinary approach to communication and has potentials for generating insights for the study of cultural communication, children and youth advocacy, children's media use, and human rights communication. However, there is currently limited attention among communication 
scholars in exploring this intellectual space for communication research and practice, thereby enhancing the much needed interdisciplinary discourse on child rights, participatory development and communication studies.

The paper attempts to bridge this gap by examining the prospects of the children's parliament as a site for multilevel communication. It demonstrates that the children's parliament has facilitated upward communication, making the voice of young people heard on major public issues, and horizontal communication, mobilizing them for participation, personal development and citizenship engagement. It also provides evidence that the modality promoted significant interagency communication among stakeholders. Nonetheless, it is constrained by several conceptual and programmatic weaknesses which vitiate its effectiveness as a tool of effective multilateral communication and meaningful participation. Besides, the approach embodies myriads of complexities and contradictions for contemporary communication practice which require further investigation. Although the initiative is perceived as a transformative instrument of social change, it is largely tokenistic, ceremonial and events-based. It is far from the expected genuine dialogue for social transformation by its exponents. Against this backdrop, the paper calls for a re-examination of the participation and communication paradigms that the children parliament model typifies.

\section{Child Participation: An Overview}

Globally, children rights to participate are enshrined in the UN Convention on the Rights which came into effect in 1989. Articles12, 13, and 15 - encapsulate the participation rights of children, including the form and conditions of their right to communicate. But Article 12 is considered as the touchstone right on their participation and communication. It reads:

1. State Parties shall assure to the child who is capable of forming his or her views the right to express those views freely in all matters affecting the child, the views of the child being given due weight in accordance with the age and maturity of the child.

2. For this purpose, the child shall in particular be provided the opportunity to be heard in any judicial and administrative proceedings affecting the child, either directly, or through a representative or an appropriate body, in a manner consistent with the procedural rules of national law. (UN CRC, 1989)

Likewise, the African Charter on the Rights and Welfare of Children embodies provisions for the participation and communication of children and young people. For example, Article 8 focuses on freedom of association while Article 9 deals with freedom of thought, conscience and religion. Nonetheless, the central provision for the communication rights of African children is enshrined in Article 7 on the freedom of expression which states as follows:

"Every child who is capable of communicating his or her own views shall be assured the rights to express his opinion freely in all matters and to disseminate his opinions subject to such restrictions as are prescribed by law" (African Charter, 1990)

From both global and regional treaties bodies cited above, children have the right to communicate and participate effectively in society. Inherent in these provisions are major communication overtones and undertones of how children should or could communicate in all facets of their lives (Fayoyin, 2011, Lansdown, 2010). But it is clear that it is characterised by numerous opportunities and tensions for multilevel communication, which are examined in this paper.

Several conceptual paradigms have been proposed to frame the implementation of participation rights. One of the earliest models is the 'Ladder of Participation' popularised by Roger Hart (1997). It highlights concepts relating to degree of tokenism or participation in social issues and the role of adults. However, the approach has been criticised as a misnomer in describing how children participate in society (Reddy \& Ratna, 2002). It is also deficient in articulating child participation within the context of African values and ethos. Another model of participation proposed by Kirby et al (2003) identifies four interacting levels of engagement as follows:

1. Children/young peoples' views are taken into account by adults

2. Children/young people are involved in decision making with adults

3. Children/young people share power and decision making with adults

4. Children/young people take autonomous decisions 
This model is non-hierarchical and non-judgemental. However, the last two levels tend to contradict African cultural and traditional practices which are still predominantly patriarchal. Putting adults and children on the same level for decision making is rather contrary to Africa's cultural values and practices. Nevertheless, their suggestion for building a culture of participation resonates with the recommendations made at the end of this chapter.

In practice, child participation is a complex concept to operationalize. It manifests various typologies of actions ranging from their involvement in reporting mechanisms (Baro, 2003), engagement in developing programmes that affect them (Landgren, 2005), involvement in various levels of governance and policy making (Guerra, 2005; Williams, 2004), and participation in international conferences (Lansdown, 2001; UNICEF, 2013). According to Save the Children (2012:43), participation entails engaging children in legal and policy reform, budget monitoring, national strategies and monitoring and reporting on government performance on international commitments.

Participation also results in different programmatic outcomes. Moore, Melchoir \& Davis (2008:254) argue that it enables children and young people to contribute to the process of social change and cultural transformation while Checkoway $(2006 ; 2011)$ suggests that it strengthens the capacity of young people to deploy their expertise for social good. Others studies highlight different outcomes, such as: how participation enhances their role in social activism and solving social problems (Bessant, 2010; Kirshner, 2007); how participation contributes to personal development and citizenship (Wood, Larson \& Brown 2009; London, Zimmerman \& Erbstein, 2003, Lansdown, 2011); how participation promotes their engagement with social processes (Ho, Clarke \& Dougherty, 2015); and how participation advances their voice in social development programming (Christens \& Dolan, 2010; Powers \& Tiffany, 2006).

However, a number of studies have argued that the participation of children and their civic engagement roles are affected by patriarchal and patronising philosophies (Akinfaderin-Akarau and Fashola, 2011; Mabala, 2011; Save the Children, 2010). Similarly, Couzens and Mtengeti (2011) and Lansdown (2010) underscore how societal presumptions of children 'incompetency' and inadequate capacity to engage affect how they communicate, participate and are perceived in society. This is consistent with Moses (2008:337) who contends that the adult domination of policy making and governance affect the ability of children in expressing opinion and influencing public decision making. Furthermore, children are romanticised as 'leaders of tomorrow', which sometimes undermines their position and voice in society today. These perceptions influence how they communicate in many cultures. In many Africa countries, entrenched beliefs and practices affect how children and young people should or could communicate in society.

Such challenges manifest in the various communication and participation activities undertaken by children and young people. Our focus in this paper is on the children parliament, one of the initiatives designed and implemented by development partners to operationalize the participation rights of children.

\section{OVERVIEW OF CHILDREN'S PARLIAMENT IN SELECTED AFRICAN COUNTRIES}

Conceptually, the children parliament aims to address what is generally regarded as the marginalisation of the voice of children young people in public discourse and to provide opportunities for them to fulfil their right to freedom of expression and freedom of association (Lansdown, 2010, UNICEF, 2008, Save the Children 2010). Practitioners argue that it improves parliament's representative function, improves legislative outcomes, and promotes civic engagement of young people (IPU and UNICEF, 2011:16). To this end, the children's parliament model is an important approach for communication and advocacy by children and young people. Children's parliaments currently exist in several countries including Nigeria, Rwanda, Zambia, Malawi, Burundi, Mozambique, DRC, Tanzania, Ghana, Sierra Leone, and Lesotho. A brief exposition on how the parliament functions in some of these countries is presented as a conceptual basis for the case study on South Africa.

In Nigeria, the children parliament was established in 2000, as a result of collaborative venture with Federal Ministry of Information and National Orientation, The Child Rights Information Bureau, the Federal Ministry of Women Affairs, Children and Social Development, UNICEF and the African Children Broadcast Network (ACBN). Since then, it has been extended and entrenched in all 36 States 
of the country and also in the Federal Capital Territory (UNICEF, 2008:3).Its goal is to promote meaningful participation of children, which is generally considered as one of the least recognised rights of children. But following years of implementation, the children parliament is now recognised by national bodies as a platform for presenting children's views on issues that concern them (UNICEF, 2008:16). Some of its achievements include contributing to the passage of the Child Rights Act in 2003, participation of members in the ECOWAS Youth Forum in 2003, raising concerns on polio controversy in 2004,calling for government action on the children and AIDS in 2006, and recommending action against child trafficking in 2007 (UNICEF, 2010). Nevertheless, a critical observation suggests that it is no more than a sporadic engagement which allows children to be seen and heard or an annual jamboree of predominantly 'children of privilege' interacting with national leaders. Although processes for effective representation of the youth population have been developed and instituted, questions need to be raised on the representativeness of the child parliamentarians (Fayoyin, 2016:7).

Another country with a long history of children's parliament is Zimbabwe. The initiative started in 1990 with the goal of allowing the voice of children from diverse social, economic, cultural and geographic backgrounds to be heard on issues that affect them (Save the Children, 2000:8). Eligibility as child parliamentarian is based on literary and debating skills, implying that only children with strong ability to communicate and debate eventually become child parliamentarians. The process naturally excludes children who may not have strong debating skills to compete for the parliament. The annual event involves engagement with political elites, including the President in the children parliament. Children involved, especially the officials are given a celebrity status during stat functions for their tenure. However, commentators have noted the hype and celebrity status of child parliamentarians do not translate into major changes for the children and the society (Antonio 2015, June 18, Newsday).

Similar efforts to enhance the voice of young people in Tanzania have resulted in the establishment of the children's council, junior council and children's parliament. According to Couzens and Mtengeti (2011:1) the establishment of the children council is intended to address the marginalization of children's voice in the Tanzanian society. It also responds to specific inhibitions to effective communication and participation of children in the country such as the traditional attitude toward young people, the perception of incompetence of children and the autocratic approach to youth participation (Couzens and Mtengeti 2011:6). Although the councils are child- led organizations, they are initiated and facilitated by adults, which also raises questions on the adult gate keeping tendencies of children opinions or the potential for outright manipulation of the process.

Malawi started the children parliament in 2002 with a focus on making "Malawi fit for children". Lamba (2002:1) noted the mechanism has enhanced children's voice on the issues of education, HIV pandemic, poverty, and orphans. Other issues that have been raised since the commencement of the children's parliament include child violence, sexual exploitation, impact of the humanitarian situation, child marriage, teen pregnancy, involvement of children in public decision making (National Aids Commission, 2009:23). But the extent to which children's voices have influenced government policies and programmes is uncertain. Thus Lamba's concern that policy discussions and government decision process require more input from children is valid (Lamba 2002).

The children's parliament in Namibia has a similar raison deter to other countries examined above. Its primary goal is to "lobby or advise government and its agencies responsible for policy making and their implementing machinery to fast track policies that would improve the rights and welfare of children and young persons in accordance with national legal instruments and international child rights provisions" (Namibia Children Parliament, 2013:4). The parliament has also debated several national and international issues such as HIV and the orphans' crisis, national budget to fund civil society organisations, lack of equipment in educational institutions and the plight of children and young persons with disability. Expectedly, the various parliamentary sessions have made Namibian children more visibility and their voice heard on diverse social issues. They have also enjoyed the participation of good will ambassadors, celebrities, and high-level government officials and the media at the annual events. But beyond well-orchestrated sessions for the visibility and voice of children, the tangible impact of the initiative requires more investigation.

In addition to the specific country initiatives, the children parliament model has evolved into a continental approach of participation and advocacy by young people. Across various sub-regions, 
similar parliaments have been established, examples being the East Africa Youth Parliament, the Mano River Union Youth Parliament and the Africa Youth Parliament (AYP). Particularly, the Africa Youth Parliament is a continental network of youth activists from 50 African countries which highlights youth issues in Africa through a strong and effective voice, increased participation of young people in national and international policy decisions and lobbying for policies that create an enabling environment for increased participation of young people in economies, societies and governance (AYP, 2011:2). The parliament also leverages social and policy change through the formation of national youth parliaments and participation in regional and international events. But due to institutional and financial challenges, most of the regional parliaments have become largely ineffective (Fayoyin, 2016:10).

From the foregoing, it is apparent that there is a significant interest among child rights advocates in enhancing how children and young people should be seen and heard in society through the child/youth parliament model. It has also become a platform for changing the perception of children and young people in Africa. While recognizing that Africa is not homogenous and that there are varying practices on how children can participate and communicate, the children parliament model has become a common feature of engagement, participation and advocacy (Couzens and Mtengeti, 2011; Lans down, 2010; UNICEF, 2008). And while the initiative has made children more visible and their voice heard in various countries, it is argued that the effectiveness of the platform as a space for meaningful participation and genuine debate and dialogue with children and young people is uncertain. An assessment by the Inter Parliamentary Union (IPU) and UNICEF describes its performance as follows: "Too often, children parliaments are one-off, symbolic events with no follow-up and hence little impact on policy or law making" (IPU, 2011:49). In many of the countries, the parliament has come up with recommendations, but there is limited evidence of implementation. Nevertheless, it is a major site for exploring multilevel participation and advocacy by African children and young people.In the following section, the paper examines three communication patterns in the South African Children's Parliament.

\section{Case Study - The South African Children's Parliament}

The South African children's parliament initiative started in 2000 under the auspices of the Nelson Mandela Children's Fund (NMCF).Conceptually, it is aimed at providing an opportunity for children from various parts of the country to meet and debate pertinent issues. The overall goal of the initiative is to serve as a tool of child to child communication and ensure that children's voice can be heard on policy and fiscal issues in society (NMCF, 2016:18). Three main communication patterns explored from the intervention are:

i. Lateral communication among young people: This involves the form and formats of communication among young people involved in the initiative. The purpose is to examine the purpose, channels and patterns of communication among them.

ii. Upward communication: This deals with how the voice of young people is being heard on social issues and brought to the policy and political domains. In principle, the goal of upward communication is advocacy; how they influence norms, social practices, regulation, resource allocation, political decisions or policies that affect children in society. Within the domain, the paper explores the extent to which upward communication is in line with traditional patterns of communication or might be perceived as promoting Western values of communication between adults and children.

iii. Interagency communication: This relates to communication process and modalities among the agencies and institutions involved in the initiative. It describes the current inter-organisational communication patterns, its challenges and how to improve stakeholder consultations and dialogue on the initiative.

Data for the case study is from secondary information, archival records, and direct observation, supplemented with 20 key informants' interviews with various partners including government agencies - Department of Social Welfare, staff of the Nelson Mandela Children's Fund, implementing partners such as UNICEF and the Debating South Africa and child ambassadors from Gauteng, Mpumalanga, Eastern Cape, Limpopo, and North West provinces. 


\section{Prospects of Lateral Communication}

As already noted, the South African Children's Parliament is aimed at promoting debate among children on issues that affect them in society. The ultimate goal is to enable them to realize their participation rights and promote their citizenship engagement. Several structures and channels exists within the children parliament to achieve this goal.

First is the Junior Council. The junior council helps to generate ideas by young people at the ward level and feed into the lateral communication processes. Second, is the child ambassadors, a group of leaders and representatives in different provinces who bring issues that affect young people to the fore at the provincial and national levels. Child ambassadors help to promote a new level of participation and civic citizenship of young people. Third is consultation at the community levels and the submission of feedback report by the ambassadors to their colleagues. The various young ambassadors and councillors are engage in regular communication of their activities and issues to their constituency. Parliamentarians also use social media as a major tool for interpersonal communication. Two commonly used platforms are Whatsapp and Facebook. Clearly, the pervasiveness of social media and information technologies has expanded opportunities and platforms for digital activism by young people in the various provinces.

\section{"We use social media to keep ourselves informed of activities of the children parliament. This promotes awareness of our activities at the national and provincial levels" (Child Ambassador from Gauteng Province)}

Children also communicate through formal and informal group communication methodologies. Workshops sponsored by implementing partners are used to enhance the knowledge on child rights issues, outreaches help them to engage with other children while regular informal face to face communication promotes group cohesion. According to key informants, the various interpersonal and group engagement processes have improved their capacity as young people to deploy their expertise for social good, encouraged them in their role as social activists and made them more socially responsible citizens in society.

"Through my interaction with other young people and consultations with our facilitators, I have been more aware of my role as an ambassador and how I can influence the lives of other young people in the province. It has improved my commitment to making a change in our community and in the lives of fellow children." (Child Ambassador for North West Province)

However there are also signs of inadequate internal communication among participants. The child parliamentarians identified inadequate logistic support as a major hindrance in their lateral communication with other members. This has also hindered their internal mobilization with other young people. Nonetheless, the deployment of digital media is enabling them for real time update and contacts on developments in the communities. Digital connectedness has also led to more 'sharing and caring' and digital activism of their agenda among themselves.

\section{Prospects of Upward Communication}

The children's parliament is also intended to amplify their voice on social, policy and political issues that affect them. Over the years, the parliament has made specific recommendations to government officials, policy makers and law makers at various levels. In 2011, the focus was on holding those in government accountable in protecting children rights, while in 2012, the parliament called on parents to spend more time with their children. It also requested the South African Police Force to review the missing persons' law provision of 48 hours to 24 hours. In 2014 it called for the accelerated implementation of interventions for children with disabilities and in light of this debate, young people with disabilities were elected in major parliamentary positions. By 2015, the parliament had reached in its $5^{\text {th }}$ cycle of deliberations and had made specific recommendations relating to upholding government accountability, establishing the ombudsman, and implementing a number of social policies. Part of the declaration and recommendation from the 2015 children parliament are outlined below (Nelson Mandela Children's Parliament 2015:1-3).

i. Forced child marriage:

- We recommend that communities should unite against forced child marriages in order to protect the rights of young girls; 
- We strongly urge that all children that have been forced into child marriages be removed in those circumstances by the department of Social Development, Safety, Security and the Police.

ii. Corporal punishment

- We recommend that parents and teachers need to find a better way to provide discipline because we believe that as children, we continuously need to be encouraged and mentored;

- We realize that corporal punishment is harmful to children, therefore, we would like to urge teachers that they are parents too and they need to exercise care love and nurturing when disciplining us as children.

iii. Safety in schools

- We realize that gang members find our schools more accessible because they easily hide their criminal activities in schools, through children who have joined gangs;

- We strongly recommend at least 1-2 police officers, a community care worker, a nurse, an emergency services can be present in schools to assist learners and teachers making the school environment a safe place for learning.

iv. Access to rights and services

- We request that the food being provided for in schools by the feeding scheme should meet the nutrition requirement and be something that is edible;

- We appreciate the rights and services that we are able to access and pledge we shall be responsible with them.

v. HIV/AIDS among children and youth

- We recommend that every school should have a child friendly clinic where they would be able to test for HIV/AIDS without being discriminated;

- We urge the state to increase the procurement of the HIV/AIDS treatment and also educate the pregnant mothers about mother to child infection.

As a tool of participation and communication, the children's parliament has been geared toward making children 'speak truth to power'. The children parliament has also enhanced the engagement of young people with national political and cultural leaders, making them more visible in society and ensuring that they are able to voice their issues. Nonetheless, the voice of young people is constrained by a number of institutional processes, the main challenge being the implementation of recommendations. While it is generally agreed that the child ambassadors are critical to unearthing issues from the local level and bringing to the national, some of the informants complained about lack of implementation of the various children's declarations. A key informant from the Free State Province said:

"The declarations from 2013 till present have not been signed. What does it tell us as children? It is clear that we only write the declaration, but it is not taken into consideration, we raise serious issues but they mean nothing to our government"

Another format of upward communication identified from the South African's children parliament is the opportunity for children to voice their issues across national frontiers. The platform has been used to exchange ideas by children from South Africa and others from the Southern African Development Council (SADC) region to discuss social and policy issues that affect them. Through their gathering, they have been able to discuss issues relating to education, child safety, politics and sexuality education (NMCF, 2016:18). Children parliamentarians from South Africa have also been facilitated to present their issues in international platforms. Over the years, partners have supported children participation to various countries the participation of South African children in international outreaches. But this tends to make privilege children more visible.

\section{Prospects of Interagency Communication}

According to different experts, inter-organizational functioning and coordination in essential in achieving social good (Doerfel, 2008; Stoner, Freeman, and Gilbert, 2009). Evidently, without effective interagency and organizational communication, achieving common goals with different organisations becomes a challenge (Ngwainmbi, 2014; Kapucu, 2005). This principle clearly 
manifests in the operations of the children parliament. Several agencies and stakeholders are involved in the design and implementation of the intervention. The principal ones are Department of Social Development, Nelson Mandela Children Fund, provincial offices, civil society organizations, community members, media the private sector and children. Through periodic interagency communication, stakeholders are able to support the vision of empowering children to fulfill their rights and mobilize a strong partners for the programme. A key informant from Gauteng noted:
"The children parliament involves series of consultations, discussions and mobilisation of all partners. The leadership of the Department of Social Development and the Nelson Mandela Children Fund has been critical in mobilizing us as stakeholders and instilled in us greater commitment to the ensuring that children rights to voice are heard in society"

Consultations and thematic discussions have also enabled all partners to internalize the common vision of the programme. Undoubtedly, the child rights mandate is a contentious issue in society, as different individuals may have divergent viewpoints. But through capacity building process, orientations and partner engagement, most implementing partners have developed a common vision of the initiative and the direction it needs to go.

However, the initiative is fraught with poor communication processes which affect the motivation and commitment of partners. Key informants identified the major communication weaknesses as limited communication flow for consistent action beyond the parliamentary sittings, lack of transparent information on key events, including the plans for the 2016 children parliament, inadequate consultation at the provincial levels after parliamentary sessions, poor support for child ambassadors to carry out their functions, significant disconnect between activities of the provinces and the national level. Thus stakeholders have not been able to maximise the power of communication due to institutional constraints. A key informant from Bloemfontein observes:

\section{"Continuous sharing of the relevant information will all partners is necessary for the future of this initiative. But when we get information just in piece-meal fashion, or just silence on the major events of the parliament, this does not augur well for the sustainability of the initiative."}

Significant agreement exists among various clusters of stakeholders on the poor inter-agency communication and engagement. From unprompted responses, child ambassadors identified disempowering effect on poor communication partners on their ability to plan and implement their activities in the provinces. Implementing partners also identified several instances of communication breakdown which have affected the progress of the initiative. Thus, it is critical for the various partners to address the communications barriers and challenges confronting the initiative.

\section{Prospects for Promoting Western Ideologies of Child Communication}

The case study investigated the potential that children parliament may be a tool that promotes Western ideologies of communication and participation. This is informed by the assumption that the children's parliament modality and some nuances of the participation agenda of development agencies reflect the Western human rights movement. However, findings from the study do not support the proposition. Key informants who have been part of its evolution affirm that the parliament does not reinforce Western patterns of child rights and communication. However, those from the NGO sector argue otherwise. A key informant suggested that the overly "donor-driven" nature of the intervention suggests that is intended to promote Western human rights ideas.

Despite the lack of agreement from key informants that the children parliament mechanism reinforces Western modality of child-adult engagement, there are aspects of the implementation which may suggest a Western philosophical approach to participation. First is the issue of holding adults and policy makers accountable to children. Clearly, this does not sound like an African engagement process. The African cultural code of engagement rarely makes provision for children to hold adults and policy makers accountable. Furthermore, within the child participation agenda, development agencies want to 'put children at the centre' of policy discussion and social issues that affect them (Save the Children, 2010). Part of the modality of achieving the goal is instructing children to be "more assertive" in public communication and parliamentary debates. Children are also expected to be bold in presenting their issues. Arguably, while children assertiveness in communication is an 
important skill in public communication, this may be misconstrued as promoting foreign idea of child -adult communication. Simultaneously, children are also expected to imbibe the major requirements for child participation such as 'respectfulness' (Lansdown, 2010:153).

The African Charter is conscious of the potential of misconstruing children rights with foreign values, hence the provision to balance children rights with responsibility in line with African values. Article 31 of the African Charter provides for the responsibility of children towards the family and society, the State and other legally recognised communities and the international community. The rationale for specifying responsibility for the child may not have been fully understood in the global human rights community, but as Kamchedzera (1999:524) argues, it can be justified conceptually within the child rights philosophy approbated by the Charter.

\section{ISSUES, IMPLICATIONS AND RECOMMENDATIONS}

From the foregoing, the children parliament is one of the numerous modalities of participation and communication in African countries. The initiative has different end goals- visibility, voice, mobilisation, networking and influence of children. The initiative thus has broader implications for communication and participation a few of which are explored below.

- The children parliament initiative provides a site for exploring multiple communication patterns, based on the multidimensional programmatic and conceptual basis. As examined in this study, it manifests horizontal, upward and network communication dynamics. It also represents a rich intellectual and interdisciplinary space for interrogating different constructs that may inform communication research, theory and practice. Thus, further investigations of the various domains of the children parliament is essential for new insights in multilevel communication approaches.

- In most societies, is generally argued that policy making is beyond the ken of children (Fayoyin, 2016; Lansdown, 2010). This perception undermines the weight to which children voice and ideas on policy issues can be considered. Therefore the episodic nature of children's parliament is a weak form of social and political engagement. It is uncertain how such sporadic modes of communication like the annual children's parliament can influence policy and cultural transformation.

- Ensuring that children and young people are heard and seen should not be limited to annual events, but should be integrated into their natural environment and daily activities. Insights and ideas on how to achieve this integrative pattern of meaningful participation and communication of children is called for. Ad-hoc modes of engagement undermine the power of genuine participation and communication.

- The rhetoric of the children participation tends to suggest that it promotes contrary values to African philosophy of child engagement. It includes expressions like 'child-led advocacy', putting children at the centre', 'holding adults accountable', 'making children more assertive', and several others. It would be critical to balance these expressions with those that promote the responsibility of children. It is impossible for participation to be a historical and apolitical. Thus the various communication and participation modalities promoted by development agencies need to be culturally and politically sensitive.

- The digital media has been integrated into the contemporary operations of the children's parliament. The digital age with multimodal approach to communication and child participation has significant implications for the traditional notion of participation and communication enshrined in the children's parliament (Fayoyin, 2011:60). From the ubiquitous availability of social media devices and multiple platforms, children are participating on daily basis and making their voice heard on various issues. This needs to be further integrated into the participation agenda of children and young people.

\section{Conclusion}

The paper sought to examine the communication implications of the children's parliament as a modality of child participation in general, and children's communication, in particular. This is based on the increasing interest of the global child rights community in making children more visible as legal entities in society, rather than as appendages. The study established that the children parliament 
has become a major platform and site for amplifying the voice of children in many African countries, including South Africa. The children's parliament also has potentials for exploring multilevel communication: lateral communication among young people, upward communication advocacy for raising issues to higher level in society for policy change and inter-organisational communication among various stakeholders involved in the process. However, it is constrained by a number of programmatic and institutional challenges. The paper calls for a re-examination of the paradigm and practices in line with the social cultural and development contexts of the African society. Further investigation on the intricate communication dimensions of the children parliament and child participation modalities will enhance the interdisciplinary approach to the study of communication and helps to bridge the gap in childhood studies, human rights, political advocacy and public communication.

\section{REFERENCES}

Akinfaderin-Agarau, F., \& Fashola, T. (2011). What business do youth have making HIV and AIDS laws in Nigeria? In H. Ashley, N. Kenton, \& A. Milligan., Young citizens: youth and participatory governnance in Africa. London: IIED.

Antonio W (18 June 2015) After Child President, one is on his own, www.newsday.co.zw. Accessed on 28 August 2016).

Beers, H. V, Invernizzi, A, \& Milne, B. (2006). Beyond Article 12: Essential Readings in Children's Participation. Thailand: Black on White Publications.

Doerfel M (2008). Inter-organisational communication. The International Encyclopedia of Communication, DOI:10.1111/b.9781405131995.2008.x

O'Donnell, D (2009). The Right of Children to be Heard: Children Rights to have their views taken into account and to participate in legal and administrative proceeding, UNICEF, Innocenti.

Fayoyin, A. (2016). Engaging Africa's Children and Young People as Advocates of their Rights in a Digital Age: Context, Complexities and Lessons, paper presented at a media advocacy workshop, 1-5 June Johannesburg,

Fayoyin, A. (2011). Promoting Children's Rights Through the New Media: The Nigerian Experience. Journal of Communication, (2) 2, 57-65.

Hodgkin, R., \& Newell, P. (2002). Implementation Handbook on the Convention on the Rights of the Child. New York: UNICEF.

IPU and UNICEF. (2011). A Handbook on Child Participation in Parliament. Geneva: IPU.

Jonnson, U. (2003). Human Rights Approach to Programming. Nairobi: UNICEF.

Kapucu, N (2005). Interagency communication networks during emergencies: boundary spanner in multiagency coordination, American Review of Public Administration, Vol. 36. (2), 207-225.

Lansdown, G (2011). Every Childs Right to be Heard UK: Save the Children.

Lansdown, G.(2010). The realistaion of Children Paricipation Rights: Critical Reflections, In A Handbook of Children and Young Persons Participation:Perspectives from Theory and Practice Percy-Smith, B and Thomas Nigel (Ed). Canada: Routledge.

Mabala, R. (2011). Youth and "the hood" - livelihoods and neighbourhoods. Environment \& Urbanization, Vol 23 (No 1), 157-181.

National Aids Commission 2009. Malawi HIV and AIDS Extended Framework 2009-20012. Lilongwe: National AIDS Commission.

Ngwainmbi, E (2014).) Healthcare Management Strategy, Communication and Development Challenges and Solutions in Developing Countries, Lexington: New York.

Save the Children. (2010). Regional Study on children's Participation in Southern Africa: South Africa, Swaziland and Zambia; Sweden: Save the Children.

Save the Children. 2000. Our Right to Be heard: voices from child parliamentarians, Harare: Save the Children.

Stoner, AF, Freeman, RE, \& Gilbert DR Jr. (2009). Management, Prentice Hall: New Jersey.

UNICEF. (2008). NCP Journey so far. Lagos: UNICEF. 